\title{
Outcomes of Aortobifemoral Bypass for TASC II C and D Aortoiliac Occlusive Disease; Lessons Learned
}

\author{
EL-SAYED A. ABD EL-MABOOD, M.D.*,** and MOHAMED F. ABDELHALIM, M.D.* \\ The Department of General \& Vascular Surgery, Faculty of Medicine, Benha University* and \\ The Department of Vascular Surgery, Benha Insurance Hospitals**, Egypt
}

\begin{abstract}
Background: Aortobifemoral Bypass (ABFB) remains effective and durable treatment option for Aortoiliac Occlusive Disease (AIOD) and of cost-benefit in our country because of high cost of endovascular intervention.

Aim of Study: To assess results of aortobifemoral bypass technique in the management of Trans-Atlantic Inter-Society Consensus II (TASC II) C and D lesions in aortoiliac segment.

Patients and Methods: This prospective study was conducted on 19 patients with symptomatic aortoiliac atherosclerotic TASC II C and D lesions. All patients were subjected to clinical evaluation, laboratory assessment, CT angiography scan, respiratory function tests and cardiac assessment by echo Doppler. Aortobifemoral bypass was performed for all patients who were divided into two groups A \& B according to type of proximal anastmosis. Follow-up period was 30 months.

Results: All patients passed uneventful intra-operative course without technical failure; midline incision was done in 12 patients $(63.2 \%)$. Proximal anastomosis was end to side in group A (13 patients (68.4\%)) and end to end in group B (6 patients $(31.6 \%)$ ). Mean operative time and $\mathrm{PO}$ hospital stay was longer in Group B: (4.6 \pm 1.9 hours, range: $3.2-5.7)$ and (7.2 \pm 2.9 days, range: $6-9$ days) respectively. Graft patency was $100 \%, 94.7 \%$ and $89.4 \%$ at 12,24 and 30 months respectively.

Conclusions: Aortobifemoral bypass is still a good option in aortoiliac occlusive disease especially complex lesions; TASC II C and D lesions as it has long durability and can be tailored to appropriately selected patients. So ABFB is still valuable technique in the field of vascular surgery.
\end{abstract}

Key Words: TASC II C and D Aortoiliac lesions - Aortobifemoral bypass - Outcomes.

\section{Introduction}

ATHEROSCLEROTIC disease of the aortoiliac segment is a common challenge reported by vas-

Correspondence to: Dr. El-Sayed A. Abd El-Mabood, The Department of General \& Vascular Surgery, Faculty of Medicine, Benha University* and The Department of Vascular Surgery, Benha Insurance Hospitals**, Egypt cular surgeons. Aortoiliac Occlusive Disease (AIOD) starts at infrarenal aortic segment and common iliac artery and progresses up and down. Progression is slow but may lead to total aortic occlusion. About one-third of patients of AIOD have significant orificial profunda femoris occlusive disease and more than $40 \%$ have significant Superficial Femoral Artery (SFA) disease [1,2].

Patterns of infra-renal aortoiliac segment atherosclerosis that need open surgery depending on TASC II classifications are TASC II C lesions that include bilateral common or external iliac artery stenoses or occlusion segment and TASC II D lesions that include infra-renal aortoiliac occlusion or diffuse disease involving infra-renal aorta and both iliac arteries in addition to common femoral artery occlusion or heavily calcified arterial wall $[3,4]$.

Isolated AIOD are generally seen in younger heavy smoker with hypercholesterolemia and its prevalence is equal in female as male and this patient has normal life expectancy. In contrast, more extensive multilevel disease are seen in older diabetics and hypertensive and are more reported in male. So patients with multisegmental disease often present with rest pain or tissue loss and manifest a reduced life expectancy. It occurs more in patients aged 45 to 65 years $[2,5]$

Diagnosis of Aortoiliac occlusive disease may be made by history and typically by axial imaging. Surgery, for inline reconstruction, with either aortic endarterectomy or bypass graft, has been the gold standard treatment modality for infra-renal aortic occlusive disease, with good long-term outcome and is well-tolerated in adequately selected patients $[2,6,7]$. 
The growing range of management options allows surgeon to tailor therapy and ongoing improvements in grafts, techniques and perioperative preparation have important role in a steady decline in post-operative morbidity and mortality. Traditional aortobifemoral grafting is performed mainly for adequately patient demographics, more complex lesions or as a secondary or tertiary technique in recurrent disease [2,8-10].

The short-and long-term results of both endarterectomy and ABFB have generally been excellent. When endarterectomy is performed for disease limited to the distal aorta and ABFB is performed for disease involving distal aorta and iliac segments, 5 -year patency rates of $95 \%$ and 10 -year rates between $85 \%$ and $90 \%$ are consistently achieved [2,11-13] .

\section{Patients and Methods}

The current study was conducted after approval from Local Ethical Committee of Benha University and Benha Insurance Hospitals and obtaining written fully informed patients consent. Patients undergoing treatment by Aortobifemoral bypass grafting for symptomatic aortoiliac atherosclerotic lesions, at the Vascular Surgery Department, Benha University and Benha Insurance Hospitals, were included in this study from January 2015 till January 2020; the enrollment period was 30 months and the patient follow-up period was 30 months.

This prospective study was conducted on 19 patients with symptomatic aortoiliac atherosclerotic TASC II C and D lesions. All patients were subjected to detailed clinical evaluation, laboratory assessment, CT Angiography scan, respiratory function tests and cardiac assessment by echo Doppler. Patients were divided into two groups according to the type of proximal anastmosis; end to side in group (A) and end to end in group (B).

Patients included in this study were patients fit for general anesthesia with combined total aortic and iliac occlusive disease, extensive calcification at aortic bifurcation as aortic wall may rupture with balloon angioplasty, aortoiliac disease involving CFA, after unsuccessful endovascular treatment, early recurrence of aortoiliac disease following angioplasty or stenting, complications of endovascular treatment, (dissection or rupture) or patients with significant renal insufficiency. But patients excluded from this study were patients with significant comorbidities (cardiac or respiratory failure) or limited life expectancy.
Steps of aortobifemoral bypass: Figs. (1-4):

ABFB grafting was performed under general anesthesia and epidural catheter was placed for post-operative pain.

The femoral vessels were exposed first through bilateral longitudinal or oblique incisions to reduce the time during which the abdomen was opened and the viscera were exposed. The distal extent of the dissection included circumferential control of proximal SFA and profunda femoris arteries. The lower parts of retroperitoneal tunnels were done with blunt digital dissection posterior to inguinal ligament and anterior to external iliac artery Figs. $(1,3)$.

Infrarenal aortic exposure was performed through a transperitoneal approach by a longitudinal midline or transverse lower abdominal laparotomy. The transverse colon was retracted cephalad and the small bowel was shifted to the patient's right side. The ligament of Treitz was then taken down, and the duodenum was mobilized to the right, allowing access to the infrarenal aorta. A fixed, self-retaining retractor was placed to aid exposure, with care taken to protect the displaced bowel from retractor blade injury Figs. $(1,3)$.

The retroperitoneal tissue overlying the aorta was dissected between superiorly left renal vein and inferiorly inferior mesenteric artery and larger lymphatic vessels here were ligated. Extensive dissection was avoided anterior to terminal aorta and proximal left iliac artery to avoid injury of the autonomic nerve plexus regulating erection and ejaculation in men. When wide area of proximal dissection was necessary due to thrombus or significant aortic calcification extending to renal arteries; proximal aortic dissection to suprarenal level or supraceliac clamping was done to allow safe proximal clamping and if distal exposure was necessary; dissection was done along right lateral side of infrarenal aorta with reflecting rather than transecting the tissue overlying.

Then the upper part of retroperitoneal tunnels was completed with further blunt digital dissection from above and below, with maintenance of a tunnel anterior to iliac arteries but posterior to ureters. Left tunnel was created to pass deep to sigmoid mesentery. Drains were passed to mark the tunnels.

After exposure and tunnel creation but before vascular control; initial dose of heparin (80 units/ $\mathrm{kg}$ ) and additional doses were given and controlled by activated clotting time (250-350 second) Figs. $(1,3)$. 
Then the aorta was carefully palpated and in asymmetrical plaque, the technique of clamping was soft plaque against hard plaque at the site of least disease to minimize risk of emboli and lessen traumatic clamp injury especially in a heavily calcified aorta. After sufficient time was allowed for circulation of heparin; distal aortic clamp was applied above or below inferior mesenteric artery and proximal clamp was applied just below the renal arteries.

In end-to-side anastomosis, all lumbar or accessory renal arteries were controlled before aortotomy to avoid back bleeding then about $3-\mathrm{cm}$ longitudinal aortotomy was created as close to renal arteries. But when end-to-end anastomosis was planned, the aorta was transected several inches below the proximal clamp and the distal aorta was oversewn in two layers with running monofilament, 3-0 polypropylene suture (Ethicon), after excision of short segment of this cuff to improve exposure of aortic neck and help precise reconstruction.

Routinely complete thromboendarterectomy of infrarenal neck was done to remove all calcified plaque and thrombotic debris so facilitating both suture placement and creation of wide anastomosis. Brief repositioning of proximal clamp to suprarenal position or application of digital pressure sufficient to temporarily occlude suprarenal aorta help clearance of all intraluminal debris. If suprarenal clamping was undertaken, concurrent clamping of renal arteries was applied to prevent inadvertent emboli. Large accessory renal artery arising from distal aorta or iliac artery and large inferior mesenteric artery were preserved in end-to-side graft or reimplanted onto the end-to-end graft.

A bifurcated graft properly sized to match aorta and femoral arteries was selected. Knitted polyester (Dacron) collagen coated grafts (FlowNit Bioseal, JOTEC GmbH, Hechingen, Germany) were used in our patients. Bifurcated grafts measuring 18 by $9 \mathrm{~mm}$ or 16 by $8 \mathrm{~mm}$ were chosen for male cases but grafts measuring 14 by $7 \mathrm{~mm}$ or even 12 by $6 \mathrm{~mm}$ were suitable for females. Type of proximal anastomosis was end-to-side or end-to-end.

For end-to-end proximal anastomosis, Fig. (2), main body of the graft was shortened to minimize graft redundancy and to allow graft limbs to straddle rather than to override transected aortic stump. Additionally for end-to-side anastomosis, Fig. (4), a beveled anastomosis was fashioned. Anastomosis was performed with running 3-0 polypropylene suture (Ethicon). Just before completion of this anastomosis, flushing with heparinized saline and adequate back flushing for any clot was allowed before re-establishment of forward flow.

After completion of proximal anastomosis, graft limbs were clamped and flushed with heparinized saline. Then they were passed through the created retroperitoneal tunnels without twisting or excess redundancy and distal anastomoses were started after proper femoral control. Longitudinal arteriotomy limited to distal CFA was done but when CFA was occluded, arteriotomy was extended across profunda femoris artery origin and femoral endarterectomy was done and closed with vein patch. Distal anastomoses were completed in a beveled end-to-side fashion with 5-0 polypropylene (Ethicon), again carrying out retrograde and antegrade flushing maneuvers before the anastomoses were completed and flow is restored. Also distal flow was restored through femoropopliteal bypass using saphenous graft or another ePTFE graft (non ringed above knee but ringed below knee (FlowLine BIPORE, JOTEC GmbH, Hechingen, Germany) or SFA stenting (Protégé Everflex self-expanding stent $6 \mathrm{~mm})$ (ev3, Plymouth, MN, U.S.A.) Figs. $(2,4)$.

Continuously anesthetic team was alerted before clamping or clamp release to control expected blood pressure changes with ischemia and reperfusion. Before wound closure, we confirmed adequate distal perfusion and absence of distal embolization using quality of pulses and Doppler signals. When revascularization was satisfactory and no further distal reconstruction was needed, effects of heparin was reversed by administration of Protamine sulfate $(1 \mathrm{mg} / 100$ units of circulating heparin) if needed for hemostasis.

After proper hemostasis, abdomen was irrigated and retroperitoneum was closed over proximal anastomosis and graft behind bowel as possible. When inadequate retroperitoneal coverage was possible, we applied a sleeve of omentum over any exposed segment of anastomosis and to separate it from adjacent bowel. This omental apron was tacked down to prevent small bowel herniation. Lastly groin wounds were irrigated and deeper tissue was closed in two layers with absorbable Vicryl sutures (Ethicon).

\section{Post-operative follow-up:}

All patients were admitted in ICU post-operative for 1-5 days to maintain proper continuous respiratory, renal and cardiac monitoring and support. Then patients were transferred to ordinary ward for abdominal and groin wound and foot care 
consisting of dressing or minor debridement. Success of the procedure depends on absence of symptoms or improvement by at least one (claudication) or two (tissue loss) categories according to Rutherford classification.

Clinical outcomes (disappearance of symptoms and healed wounds), patency rates, patient survival (procedure related one month mortality) and complications following the procedure were reported. All patients were followed for 30 months with regular visits at 1, 12, 24 and 30 months. Followup was in the form of clinical examination and duplex US \pm CT angiography if needed in cases of absent or diminished pulse or recurrence of symptoms.
Statistical analysis: Statistics sequence was generated by an independent statistician. Collected data were tabulated and analyzed using SPSS version 16 soft ware (SpssInc., Chicago, ILL Company) and Microstat W software (India, CNET Download.com). Categorical data were presented as number and percentages, using Fisher's Exact test (FET). Continuous data were expressed as mean \pm standard deviation and range. Differences between groups were tested using ANOVA (F-test) for variables or Kruskal Wallis (KW) test for non parametric ones. $(p<0.05$ was considered significant).

These all data were shown in the following pictures:

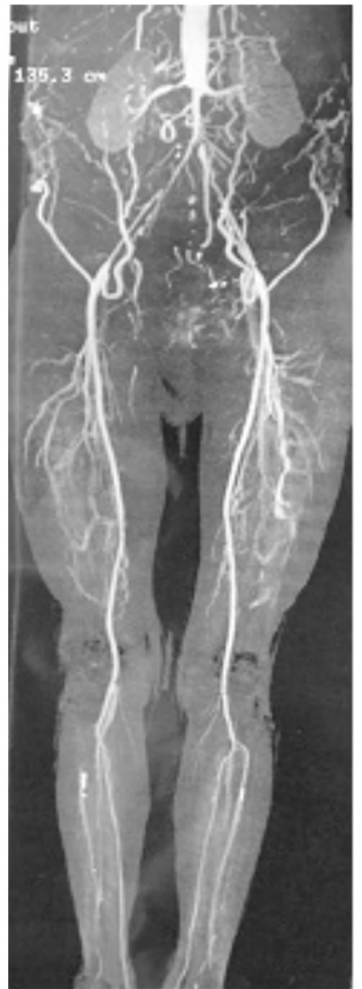

CT Angiography

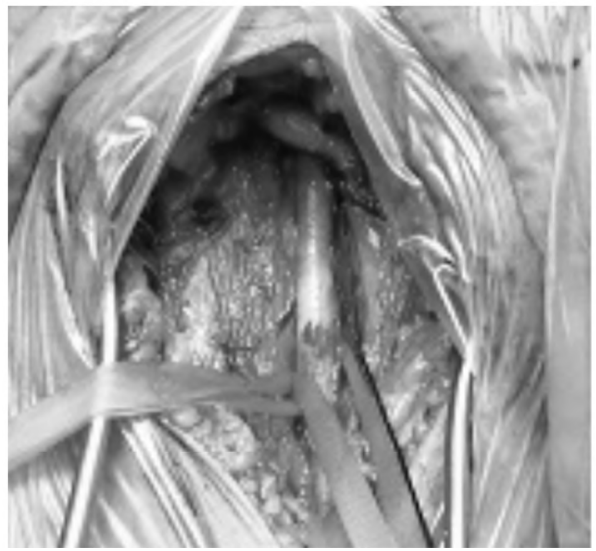

Rt femoral
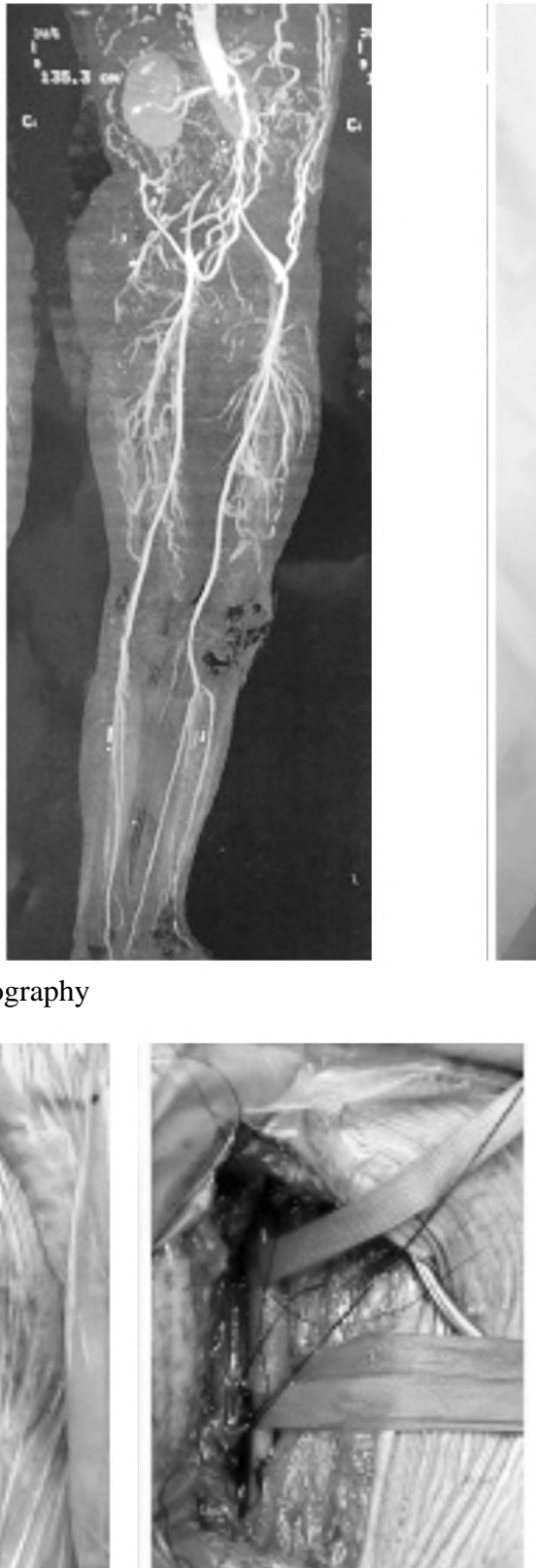

Lt femoral

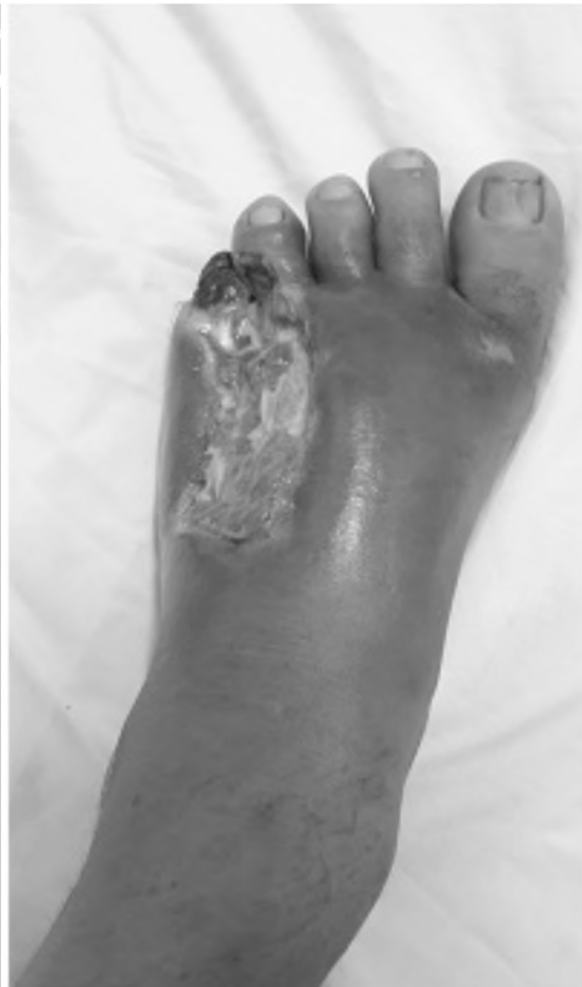

Left foot of the patient

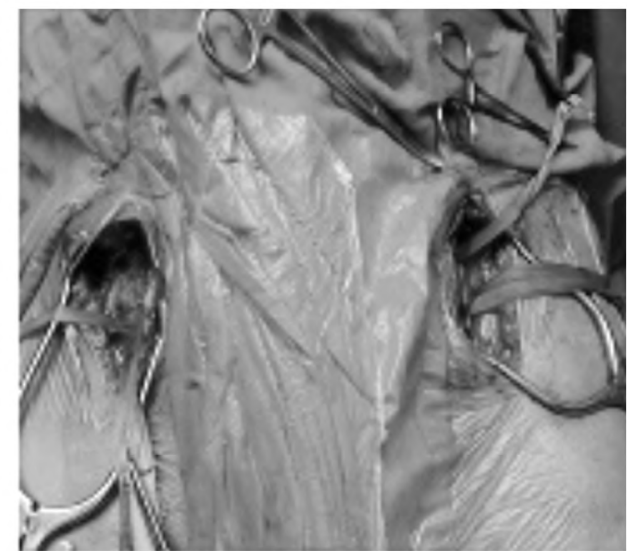

Bilateral femoral 


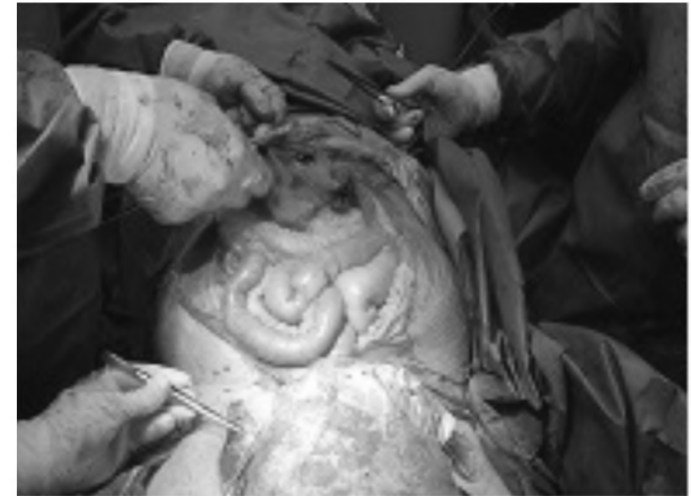

Midline incision

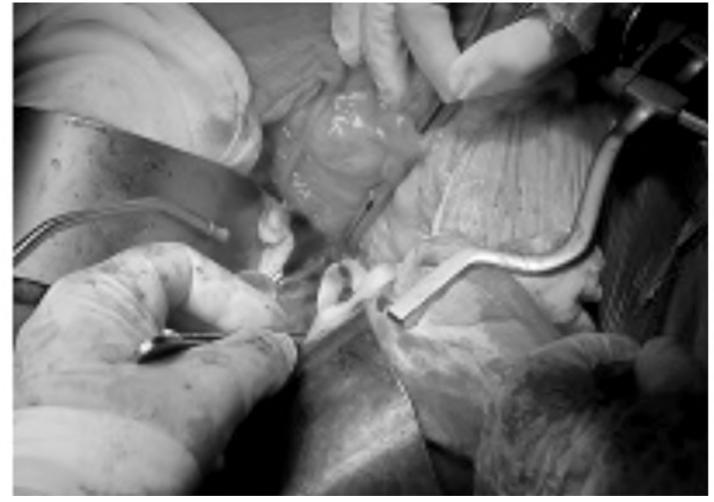

Dissection of retroperitoneum

Fig. (1): Pre-operative data with both proximal and distal exposure of case (1).

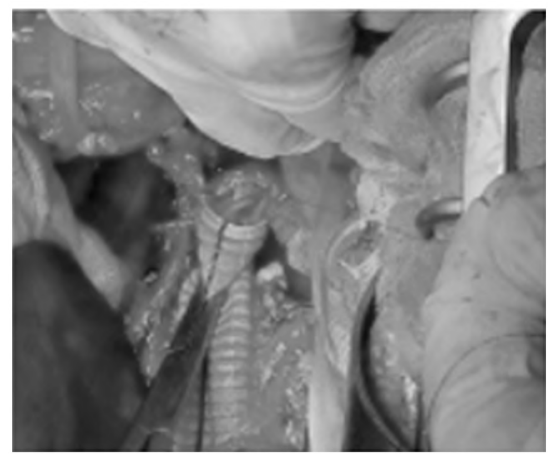

End to end anastmosis

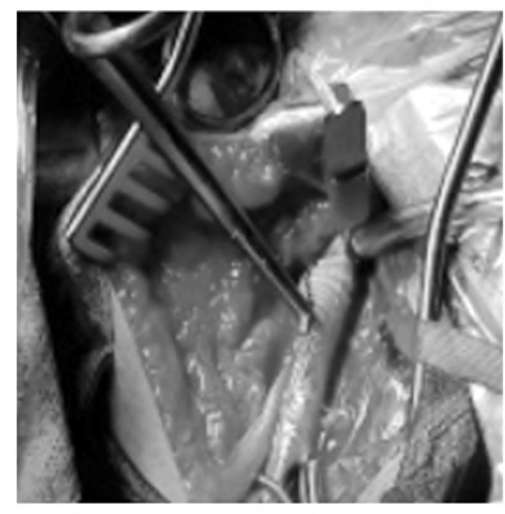

Lt femoral anastmosis

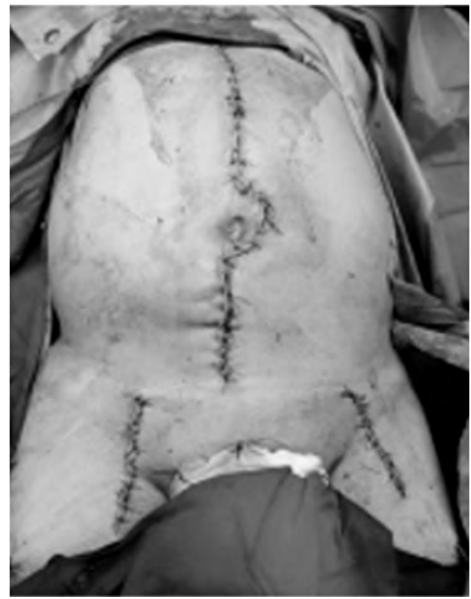

Immediate post-operative

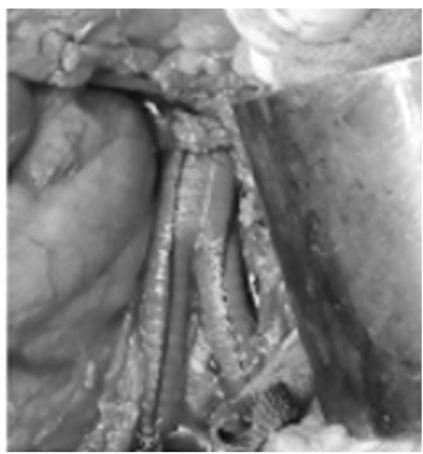

Complete anastmosis

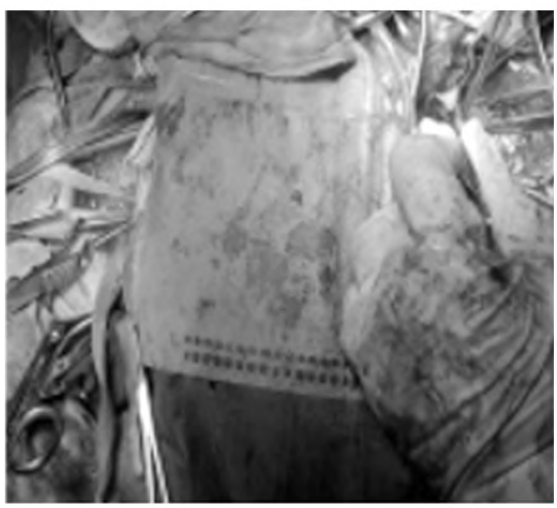

Bilateral anastmosis

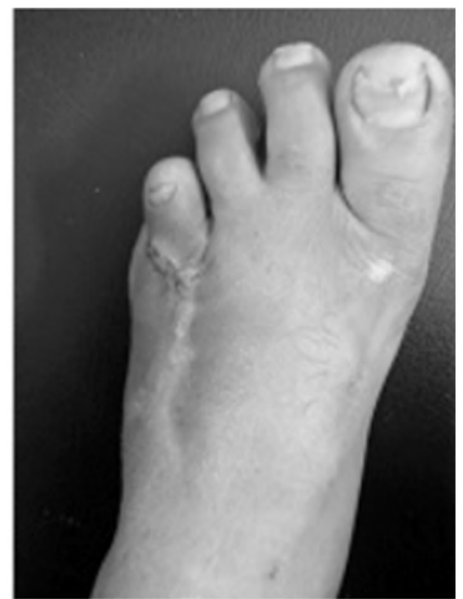

Lt foot after 3 months

Fig. (2): Proximal and distal anastomosis with post-operative data of case (1). 


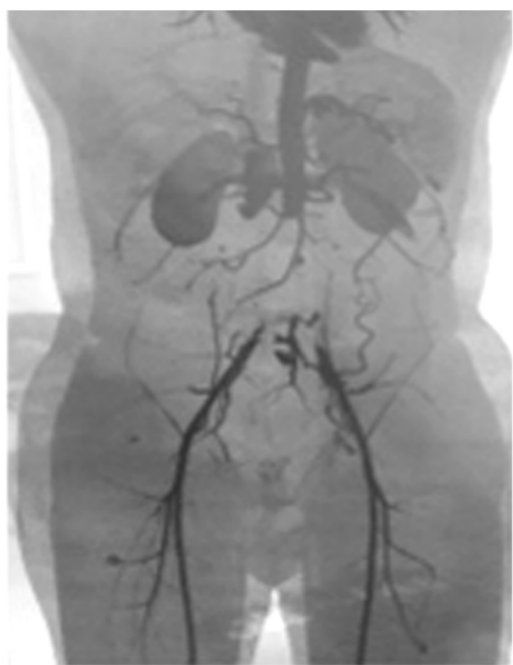

CT Angiography

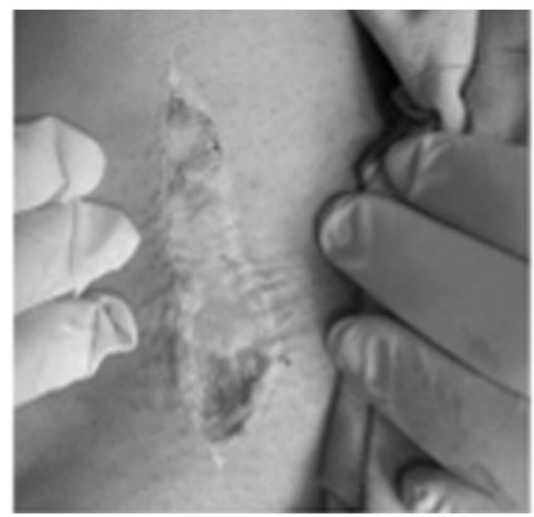

Rt femoral
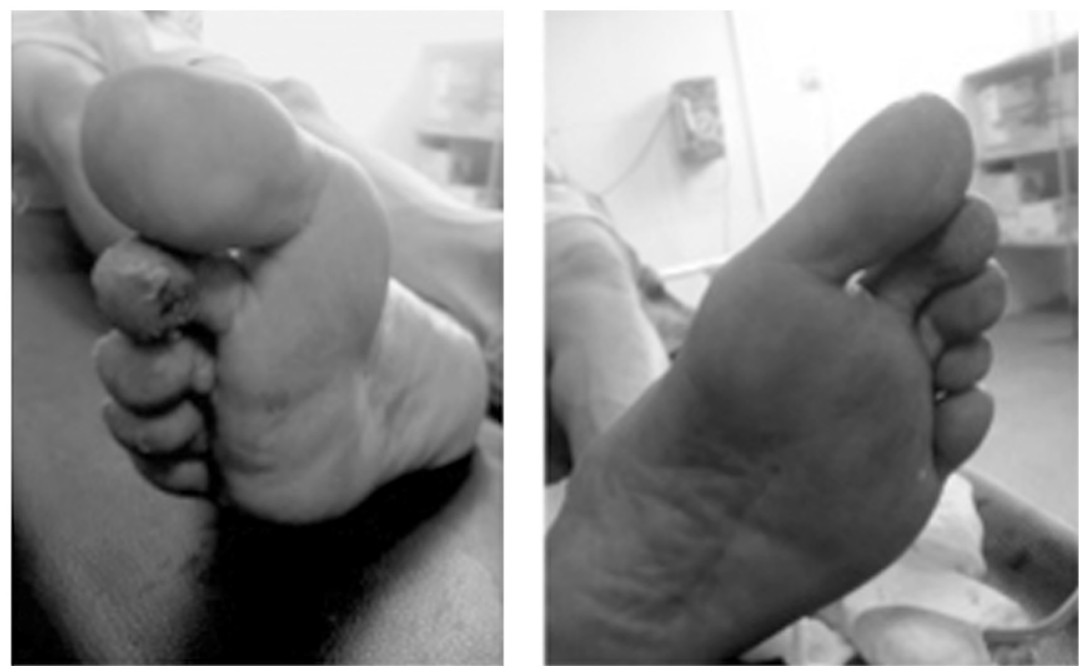

Both feet of the patient

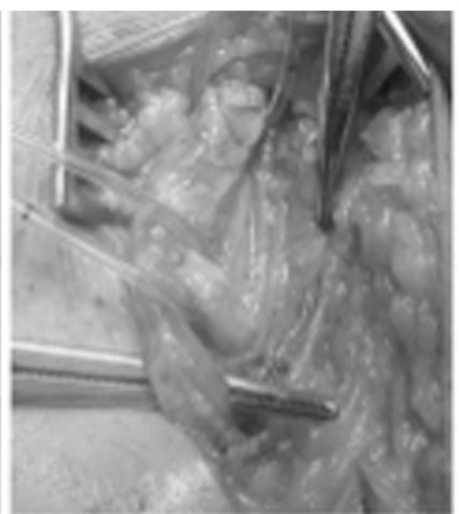

Lt femoral

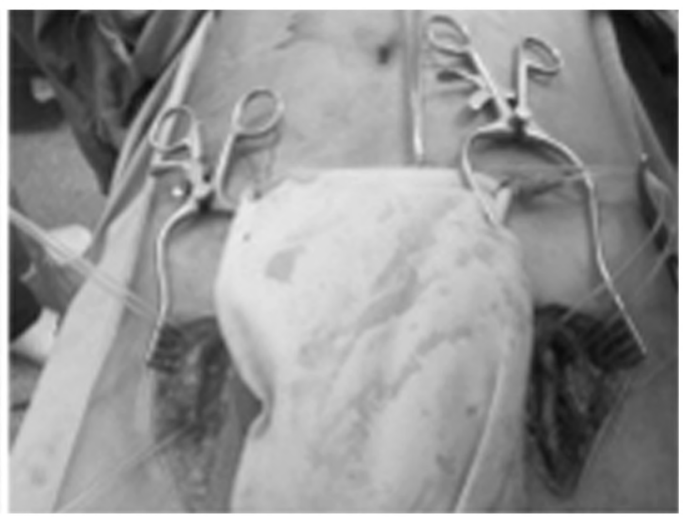

Bilateral femoral

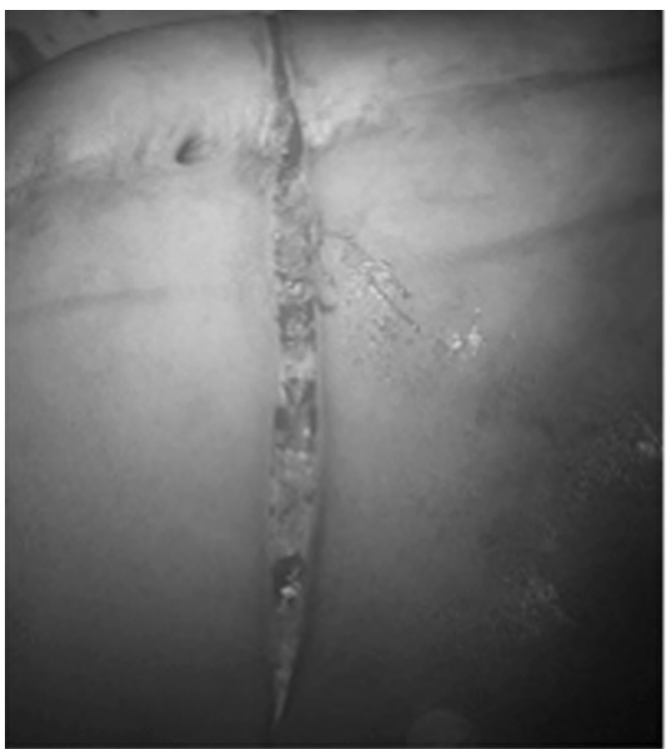

Transverse incision

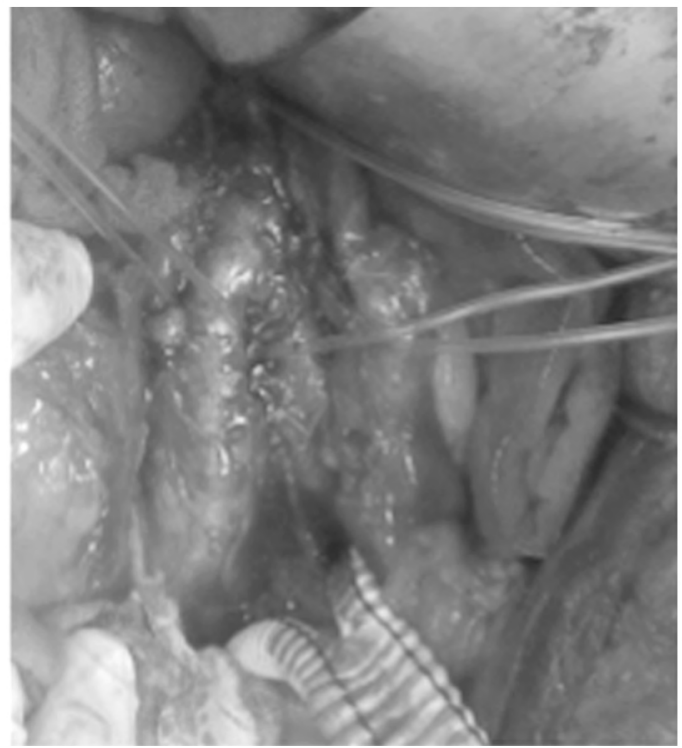

Completely exposed aorta

Fig. (3): Pre-operative data with both proximal and distal exposure of case (2). 


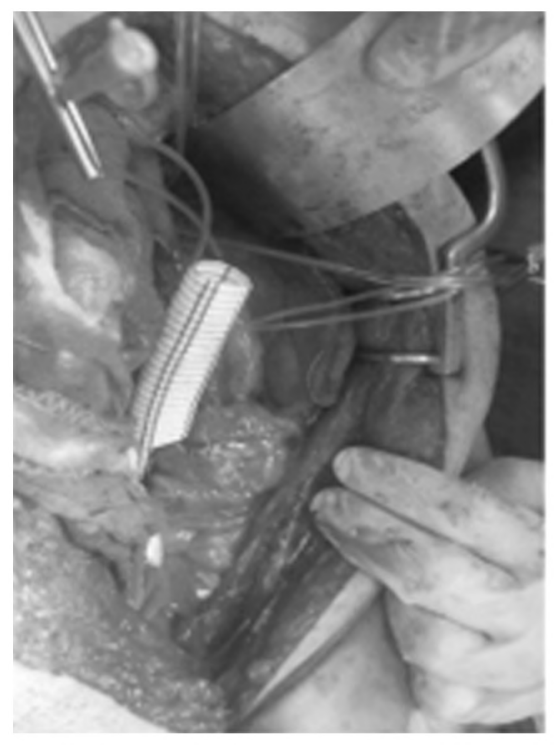

End to side anastmosis

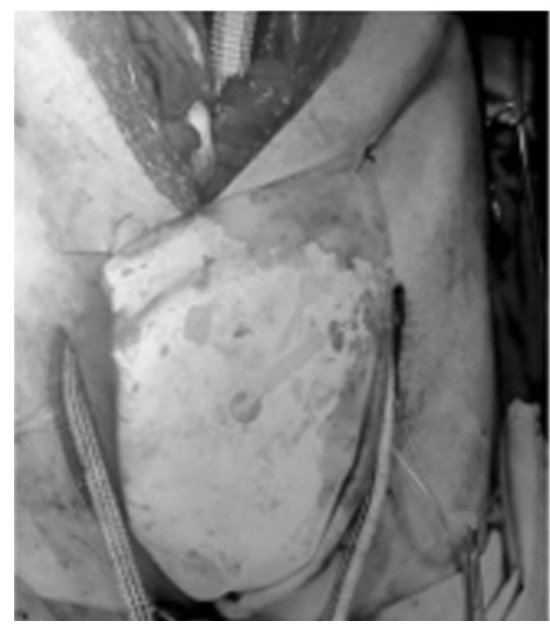

Bilateral graft tunneling

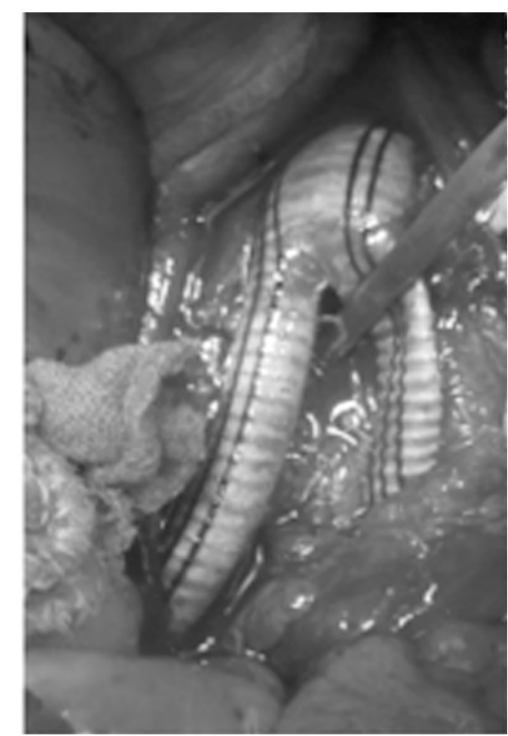

Complete anastmosis

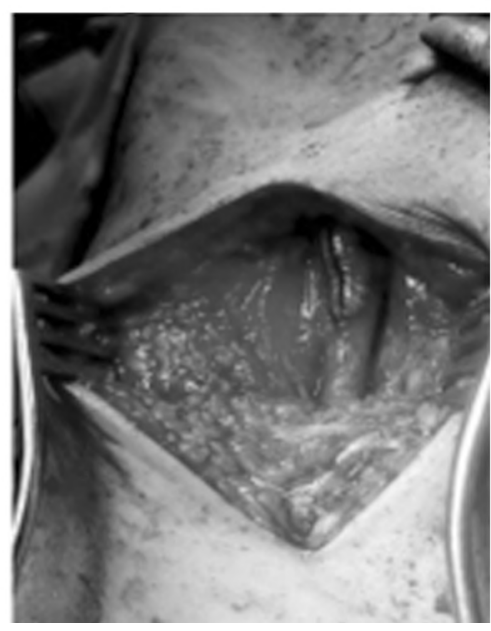

Lt femoral anastmosis

Fig. (4): Proximal and distal anastomosis with post-operative data of case (2).

\section{Results}

The current study was conducted on 19 patients with symptomatic aortoiliac atherosclerotic TASC II C and D lesions. The mean age was $64.7 \pm 9.21$ (51-73) years old and (57.9\%) of them were males. Most patients 13 (68.4\%) were ASA II. Five patients have received previous endovascular intervention. Clinical presentation was mainly ischemic rest pain [9 patients $(47.4 \%)$ ] (Table 1).

By reviewing the lesion characteristics; most lesions were TASC II D lesions in 16 patients $(84.2 \%)$. There were associated femoral lesions was observed in 12 patients $(63.2 \%)$ (Table 2$)$.

All patients passed uneventful intra-operative course without technical failure; abdominal incision was mainly midline in 12 patients $(63.2 \%)$ and the proximal anastomosis was end to side in group A (13 patients $(68.4 \%)$ ) and end to end in group B (6 patients (31.6\%)) (Table 3), Fig. (5).

As regard to operative data; mean operative time was longer in patients of Group B: $6.3 \pm 1.56$ hours, range: 4.5-7 hours. Intra-operative blood loss was more also in patients of Group B. Mean duration of $\mathrm{PO}$ hospital stay was longer in patients of Group B: $9.7 \pm 3.4$ days, range: 6-15 days (Table

$$
\text { (). }
$$

st There was one patient (5.3\%) who died in the $1^{\text {st }}$ week post-operative due to massive myocardial infarction. Graft patency was $100 \%, 94.7 \%$ and $89.5 \%$ at 12,24 and 30 months respectively. In addition to systemic and local complications (Table 
Table (1): Patients' demographic data.

\begin{tabular}{ll}
\hline Data & \multicolumn{1}{c}{ Fidings } \\
Number $(\%)$
\end{tabular}

More than one risk factor \& co-morbidity was observed in one patient. Data are presented as numbers; percentages \& ranges are in parenthesis.
Table (2): Lesion characteristics.

\begin{tabular}{ll}
\hline Data & $\begin{array}{c}\text { Fidings } \\
\text { Number }(\%)\end{array}$ \\
\hline TASC II lesions: & \\
Class (C) & $3(15.8 \%)$ \\
Class (D) & $16(84.2 \%)$ \\
Associated femoral lesions: & \\
Right limb & $4(21.1 \%)$ \\
Left limb & $5(26.3 \%)$ \\
Bilateral limbs & $3(15.8 \%)$ \\
\hline Data are presented as numbers; percentages \& ranges are in parenthesis.
\end{tabular}

Data are presented as numbers; percentages \& ranges are in parenthesis.

Table (3): Intraoperative events.

\begin{tabular}{ll}
\hline Data & \multicolumn{1}{c}{$\begin{array}{c}\text { Fidings } \\
\text { Number }(\%)\end{array}$} \\
\hline Abdominal incision: & $12(63.3 \%)$ \\
Midline & $7(36.7 \%)$ \\
Transverse & \\
Configuration of proximal anastomosis: & $13(68.4 \%)$ \\
Group (A); end to side & $6(31.6 \%)$ \\
Group (B); end to end & \\
Left renal vein: & $3(15.8 \%)$ \\
Division and ligation & $16(84.2 \%)$ \\
Retraction & $4(21.1 \%)$ \\
Repair due to tear & \\
Distal revascularization: & $9(47.4 \%)$ \\
Adjunctive profundaplasty & $3(15.8 \%)$ \\
Femoropopliteal bypass & $1(5.3 \%)$ \\
SFA stenting &
\end{tabular}

Data are presented as numbers; percentages \& ranges are in parenthesis.

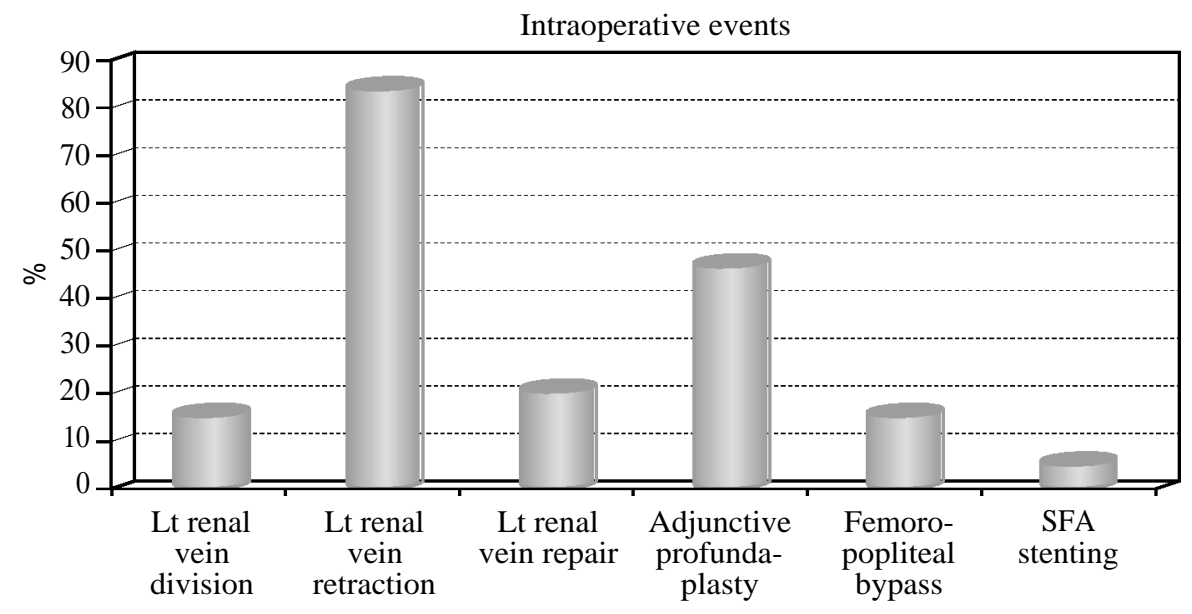

Fig. (5): Graph of intraoperative events.

Table (4): Operative and immediate post-operative (PO) data.

\begin{tabular}{|c|c|c|c|c|}
\hline Variables & $\begin{array}{c}\text { Group A } \\
\mathrm{N}=13(68.4 \%)\end{array}$ & $\begin{array}{c}\text { Group B } \\
\mathrm{N}=6(31.6 \%)\end{array}$ & ANOVA & $\begin{array}{c}p- \\
\text { value }\end{array}$ \\
\hline $\begin{array}{l}\text { - Operative time (hours) } \\
(\text { mean } \pm \text { SD) }\end{array}$ & $\begin{array}{l}3.2 \pm 1.2 \\
(2.1-4.3)\end{array}$ & $\begin{array}{l}4.6 \pm 1.9 \\
(3.2-5.7)\end{array}$ & 18.6 & $0.003(\mathrm{~S})$ \\
\hline $\begin{array}{l}\text { - Intra-operative blood } \\
\text { loss (ml) (mean } \pm \text { SD) }\end{array}$ & $\begin{array}{l}700 \pm 250 \\
(450-1300)\end{array}$ & $\begin{array}{l}1000 \pm 450 \\
(800-1900)\end{array}$ & $\mathrm{KW}=10.98$ & $0.004(\mathrm{~S})$ \\
\hline $\begin{array}{l}\text { - Duration of PO hospital } \\
\text { stay (days) (mean } \pm \text { SD) }\end{array}$ & $\begin{array}{l}5.7 \pm .2 .1 \\
(4-6)\end{array}$ & $\begin{array}{l}7.2 \pm 2.9 \\
(6-9)\end{array}$ & $\mathrm{KW}=11.9$ & $0.005(\mathrm{~S})$ \\
\hline
\end{tabular}

- Data are presented as means \pm SD \& number; ranges and percentages are in parenthesis and statistically significant difference by using ANOVA \& KW-test. 
Table (5): Outcomes during the follow-up period (30 months).

\begin{tabular}{|c|c|}
\hline Outcomes & $\begin{array}{c}\text { Fidings } \\
\text { Number }(\%)\end{array}$ \\
\hline \multicolumn{2}{|l|}{ During 1st month } \\
\hline 30 day mortality & $1(5.3 \%)$ \\
\hline $\begin{array}{l}\text { Systemic complications: } \\
\text { Cardiac (infarction) } \\
\text { Respiratory (pulmonary edema) } \\
\text { Renal impairment } \\
\text { Gastrointestinal ischemia without perforation }\end{array}$ & $\begin{array}{l}3(15.8 \%) \\
4(21.1 \%) \\
1(5.3 \%) \\
1(5.3 \%)\end{array}$ \\
\hline $\begin{array}{l}\text { Local complications: } \\
\text { Retroperitoneal hematoma } \\
\text { Groin hematoma } \\
\text { Wound infection } \\
\text { Graft infection } \\
\text { Lymphatic leak } \\
\text { Bowel injury }\end{array}$ & $\begin{array}{l}3(15.8 \%) \\
4(21.1 \%) \\
2(10.5 \%) \\
0(0 \%) \\
3(15.8 \%) \\
1(5.3 \%)\end{array}$ \\
\hline \multicolumn{2}{|l|}{ After 12 months } \\
\hline $\begin{array}{l}\text { Local complications: } \\
\text { Incisional hernia } \\
\text { Groin wound dehiscence }\end{array}$ & $\begin{array}{l}4(21.1 \%) \\
3(15.8 \%)\end{array}$ \\
\hline \multicolumn{2}{|l|}{ After 24 months } \\
\hline $\begin{array}{l}\text { Local complications: } \\
\text { Graft occlusion }\end{array}$ & $1(5.3 \%)$ \\
\hline \multicolumn{2}{|l|}{ After 30 months } \\
\hline $\begin{array}{l}\text { Local complications: } \\
\text { Graft occlusion }\end{array}$ & $1(5.3 \%)$ \\
\hline
\end{tabular}

\section{Discussion}

There is a document by second Trans-Atlantic Inter-Society Consensus on treatment of Peripheral Arterial Disease (TASCII) concluded that aortobifemoral bypass is still the mainstay of treatment for severe and diffuse aortoiliac occlusive disease (AIOD) TASC II grade C and D. Since "Oudot" performed the first open aortobifemoral bypass in 1950 , the advances in vascular field and prostheses have created many changes in this procedure. Open AIOD surgery is still a durable treatment options despite it is associated with a high morbidity and mortality $[\mathbf{3 , 7 , 1 4 ]}$.

Atherosclerotic disease of aortoiliac segment is considered the commonest challenge facing the vascular surgeons. Aortobifemoral (ABFB) bypass grafting and open endarterectomy remain effective and durable treatment options for aortoiliac occlusive disease (AIOD) $[\mathbf{1 , 2 , 1 3 ]}$.

In the current study, all patients were (51-73) years old with mean age was $64.7 \pm 9.21$ years and $(57.8 \%)$ of them were males; this result was comparable to a study done by "DeCarlo et al." [15] who mentioned that mean age was $67.9 \pm 10.6$ years and $51.2 \%$ were women. In our study males were more than females because males were heavy smokers. Also this result was comparable to a study done by "McPhee et al." who mentioned that mean age was $59.9 \pm 6.6$ years but males were $98.8 \%$ [16] This result was near similar to results reported by "Kakkos et al."; where the mean age was 66 (5870) years [17]. This age group can be explained by "atherosclerosis is aging process" [2,18] .

Clinical presentation in this study was mainly ischemic rest pain in 9 patients $(47.4 \%)$; these symptoms were more than that reported by "Dorigo et al."; (28\%) and slightly more than that reported by "Kakkos et al."; (32\%) [13,17]. Most patients (68.4\%) of this study were ASA II and five patients $(26.3 \%)$ have received previous endovascular intervention; these results were comparable to study done by "Lecot et al." who reported (49.4\%) and (33.3\%) respectively [14]

Comorbidities and risk factors were defined by "Pulli et al." [19]. In the current study, the most common risk factors were active smoking in (68.4\%), hyperlipidemia in (47.4\%) and systemic hypertension in $(36.7 \%)$. These finding were comparable to reports of "Lecot et al."; (82.7\%), (63.2\%) and (55.2\%) and "Kakkos et al."; (79\%), $(77 \%)$ and $(63 \%)$ respectively $[\mathbf{1 4 , 1 7 ]}$.

There were many indications of aortobifemoral bypass; heavily calcified aorta was one of the main indications for this surgery in addition to the lesion characteristics [20]. In our study, most lesions were TASC II D lesions in 16 patients (84.2\%); this was near that described by "DeCarlo et al." (89.8\%). This finding can be explained by "TASC II D lesions are complex lesions with high rate of failure and complications of endovascular interventions" [15].

All patients passed uneventful intra-operative course without technical failure; abdominal incision was mainly midline in 12 patients $(63.2 \%)$ despite patients with transverse incision experience less postoperative pain. The proximal anastomosis was end to side in 13 patients (68.4\%) and end to end in 6 patients $(31.6 \%)$. End-to-side anastomosis was mandatory in occluded external iliac arteries but patent internal and common iliac arteries; to avoid loss of pelvic perfusion leading hip claudication up to severe buttock rest pain or ulceration $[21,22]$, in addition to erectile dysfunction and rarely seen paraplegia secondary to spinal cord ischemia [23]. Despite end-to-end anastomosis was longer operation with more blood loss; it had many ben- 
efits; easy thromboendarterectomy of infra renal aortic cuff and no flow turbulence. Further, this graft was more flat enhancing retroperitoneum coverage so reducing aortoenteric fistulae and graft infection. In addition to oversewing of distal stump had lower risk of clamp related emboli [24].

For adequate exposure of juxtarenal aorta; cephalad or caudal retraction of left renal vein was done. There was tear in the left renal vein during its mobilization and was repaired by running 5-0 polypropylene suture (Ethicon) in 4 patients $(21.1 \%)$. Division of this vein was done in 3 patients (15.8\%) with preservation of adrenal, lumbar, and gonadal collateral branches for additional exposure of aorta and proper clamping.

Knitted polyester (Dacron) grafts were preferred due to excellent handling and hemostatic properties in addition to it develops a more stable pseudointima as reported by "Nunn et al." [25]. Proper tunneling and sizing of the graft to the runoff vessels were a must to avoid limb thrombosis secondary to slow flow from twisting or oversizing as mentioned by "Hertzer et al. and Salvatore et al." [26,27]

In the current study; distal anastomosis was performed end to side to the Common Femoral Artery (CFA) in 7 patients (36.8\%) with normal proximal SFA and profunda femoris arteries. But distal revascularization was performed in 12 patients (63.2\%); femoropopliteal bypass was done in 3 patients (15.8\%) with long lesion, SFA stenting was performed in 1 patient $(5.3 \%)$ with short lesion and adjunctive profundaplasty was done in 9 patients $(47.4 \%)$. These results depended on the fact mentioned by [28-30] that adjunctive profundaplasty may be sufficient to prevent graft thrombosis and to salvage the limb especially with good collateral to popliteal artery. Also these results were supported by "Patel et al." who reported "endovascular interventions have not increased the complexity of open aortic surgery performed for AIOD' [31,32].

There was one patient (5.3\%) who died in the 1 st week due to massive myocardial infarction. This result was comparable to "Lecot et al."; who reported 30 day post-operative mortality was one patient $(1.1 \%)$ due to persisting acute renal failure, pneumonia, and myocardial infarction; despite maximal supportive, the patient died after 18 days. Also this result was comparable to "McPhee et al."; who mentioned; 10 patients $(2.7 \%)$ mortality $[14,16]$

As regard to systemic complications during the 1 month post-operative; Myocardial Infarction (MI) in 3 patients (15.8\%), respiratory (pulmonary edema) in 4 patients $(21.1 \%)$, renal impairment and gastrointestinal ischemia without perforation in one patient $(5.25 \%)$ were reported and these results were comparable to "DeCarlo et al."; who observed postoperative MI in 16 patients (6.3\%), Respiratory failure in 19 patients (7.4\%) and postoperative mesenteric ischemia in 5 patients $(2 \%)$ [15].

By reviewing local complications during the 1 st month post-operative; there were bleeding complications (retroperitoneal hematoma in $3 \mathrm{pa}-$ tients (15.8\%); one of them was treated by surgical drainage and the other two patients were treated conservatively and groin hematoma in 4 patients $(21.1 \%)$; treated conservatively), wound infection in 2 patients $(10.5 \%)$; (treated with proper antibiotics), bowel injury in the form of serosal tear was reported in one patient $(5.25 \%)$; (treated with suture closure) and lymphatic leak in 3 patients (15.8\%); (treated conservatively). But there was no graft infection; these result were comparable to "Dorigo et al." who reported retroperitoneal hematoma in $1 / 80$ patients $(1.25 \%)$, femoral hematoma in $4 / 80$ patients $(5 \%)$ and wound infection in $2 / 80$ patients (2.5\%) [13] . But lymphatic leak was observed by "Lecot et al." in 3 patients (3.4\%) [14]. And bowel injury was observed by "DeCarlo et al." in 2 patients $(0.8 \%)[15]$.

After 12 months; local complications included incisional hernia (treated with mesh repair) in 4 patients $(21.1 \%)$, groin wound dehiscence (treated with sartorius flap) in 3 patients (15.8\%). After 24 months; there was graft occlusion in one patient $(5.3 \%)$ (treated with axillobifemoral bypass). After 30 months; there was graft occlusion in one patient (5.3\%) (treated with axillobifemoral bypass); this graft occlusion was secondary to disease progression in the infrarenal aortic cuff so in all cases; reconstruction close to renal arteries is mandatory as described by Matthew et al. [2].

\section{Conclusion:}

Aortobifemoral bypass is still a good option in aortoiliac occlusive disease especially complex lesions; TASC II C and D lesions as it has long durability and can be tailored to appropriately selected patients. So ABFB is still valuable technique in the field of vascular surgery.

\section{References}

1- BACK M.R., JOHNSON B.L., SHAMES M.L. and BANDYK D.F.: Evolving complexity of open aortofemoral reconstruction done for occlusive disease in the endovascular era. Ann. Vasc. Surg., 17: 596-603, 2003. 
2- MATTHEW T., SAMIR K. and MICHAEL B.: Aortoiliac Disease, Direct Reconstruction; Rutherford's vascular surgery and endovascular therapy 9 th by Anton N. S. and Bruce A.P.; Printed in China; 2 (106): 4623-40, 2018.

3- NORGREN L., HIATT W., DORMANDY J., NEHLER M., HARRIS K. and FOWKES F.: Inter-society consensus for the management of peripheral arterial disease (TASC II). J. Vasc. Surg., 45 (Suppl. S): S5-67, 2007.

4- HANS S., DESANTIS D., SIDDIQUI R. and KHOURY M.: Results of endovascular therapy and aortobifemoral grafting for Transatlantic Inter-Society type C and D aortoiliac occlusive disease. Surgery, 144: 583e9, 2008.

5- SUGGS W., VEITH F. and SANCHEZ L.: Surgical Treatment of Occlusive Vascular Disease in Elderly. Principles \& Practice of Geriatric Surgery, pp.: 475-9, 2001.

6- BREWSTER D.C.: Clinical \& anatomical considerations for surgery in aorto-iliac disease and results of surgical treatment. Circulation; 83 (Suppl.): 42-52, 1991.

7- INDES J., PFAFF M., FARROKHYAR F., BROWN H., HASHIM P. and CHEUNG K.: Clinical outcomes of 5358 patients undergoing direct open bypass or endovascular treatment for aortoiliac occlusive disease: A systematic review and meta-analysis. J. Endovasc. Ther., 20: 443$55,2013$.

8- STATHER P., SIDLOFF D., DATTANI N., CHOKE E., BOWN M. and SAYERS R.: Systematic review and metaanalysis of the early and late outcomes of open and endovascular repair of abdominal aortic aneurysm. Br. J. Surg., 100: 863-72, 2013.

9- HERTZER N.R., BENA J.F. and KARAFA M.T.: A personal experience with direct reconstruction and extraanatomic bypass for aortoiliofemoral occlusive disease. J. Vasc. Surg., 45: 527e35, 2007.

10- KASHYAP V.S., PAVKOV M.L., BENA J.F., SARAC T.P., O'HARA P.J. and LYDEN S.P.: The management of severe aortoiliac occlusive disease: Endovascular therapy rivals open reconstruction. J. Vasc. Surg., 48: 1451e7. 57 e1-3, 2008.

11-INDES J., MANDAWAT A., TUGGLE C., MUHS B. and SOSA J.: Endovascular procedures for aorto-iliac occlusive disease are associated with superior short-term clinical and economic outcomes compared with open surgery in the inpatient population. J. Vasc. Surg., 52: 1173-9. 1179.e1171, 2010.

12- BURKE C., HENKE P., HERNANDEZ R., RECTENWALD J., KRISHNAMURTHY V. and ENGLESBE M. A contemporary comparison of aortofemoral bypass and aortoiliac stenting in the treatment of aortoiliac occlusive disease. Ann. Vasc. Surg., 24: 4e13, 2010.

13-DORIGO W., PIFFARETTI G., BENEDETTO F., TARALLO A., CASTELLI P., SPINELLI F., FARGION A. and PRATESI C.: Comparison between aortobifemoral bypass and aortoiliac kissing stents in patients with complex aortoiliac obstructive disease. J. Vasc. Surg., 65: 99-107, 2017.

14- LECOT F., SABBE T., HOUTHOOFD S., DAENENS K. and FOURNEAU I.: Long-term Results of Totally Laparoscopic Aortobifemoral Bypass Eur. J. Vasc. Endovasc. Surg., 52: 581e587, 2016.
15- DeCARLO C., BOITANO T., SCHWARTZ S., TODD LANCASTER R., CONRAD F., EAGLETON M., BREWSTER C. and CLOUSE W.: Operative Complexity and Prior Endovascular Intervention Negatively Impact Morbidity after Aortobifemoral Bypass in the Modern Era; Boston, Massachusetts; Ann. Vasc. Surg., 62: 21-9, 2020.

16- McPHEE T., MADENCI A., RAFFETTO J., MARTIN M. and GUPTA N.: Contemporary comparison of aortofemoral bypass to alternative inflow procedures in the Veteran population; West Roxbury and Boston; J. Vasc. Surg., 64: 1660-6, 2016.

17- KAKKOS S.K., HAURANI M.J., SHEPARD A.D., NYPAVER T.J., REDDY D.J., WEAVER M.R., LIN J.C. and HADDAD G.K.: Patterns and Outcomes of Aortofemoral Bypass Grafting in the Era of Endovascular Interventions Eur. J. Vasc. Endovasc. Surg., 42: 658-66, 2011.

18- REED A.B., CONTE M.S., DONALDSON M.C., MANNICK J.A., WHITTEMORE A.D. and BELKIN M.A. The impact of patient age and aortic size on the results of aortobifemoral bypass grafting. J. Vasc. Surg., 37: 1219-25, 2003

19- PULLI R., DORIGO W., FARGION A., ANGILETTA D., AZAS L. and PRATESI G.: Early and midterm results of kissing stent technique in the management of aortoiliac obstructive disease. Ann. Vasc. Surg., 29: 543-50, 2015.

20- KASHYAP V.S., PAVKOV M.L., BENA J.F., SARAC T.P., O'HARA P.J. and LYDEN S.P.: The management of severe aortoiliac occlusive disease: Endovascular therapy rivals open reconstruction. J. Vasc. Surg., 48: 1451-7, 2008.

21- JAQUINANDI V., PICQUET J., SAUMET J., BENHAR ASH P., LEFTHERIOTIS G. and ABRAHAM P.: Functional assessment at the buttock level of the effect of aortobifemoral bypass surgery. Ann. Surg., 247: 869 2008.

22- JAQUINANDI V., PICQUET J., BOUYÉ P., SAUMET J., LEFTHERIOTIS G. and ABRAHAM P.: High prevalence of proximal claudication among patients with patent aortobifemoral bypasses. J. Vasc. Surg., 45 (2): 312-8, 2007.

23- ANTONIA H.C., SCHREUDER T.F., FENNIS J.A. and TEIJINK P.J.: Lumbosacral plexopathy associated with aortoiliac occlusive disease surgery. Journal of Neurology, 254: 803, 2007.

24- MADIBA T., MARS M. and ROBBS J.: Choosing the proximal anastomosis in aortobifemoral bypass. B.J.S., 84 (10): 1416-8, 2005

25- NUNN D.B., CARTER M.M., DONOHUE M.T. and HUDGINS P.C.: Post-operative dilation of knitted Dacron aortic bifurcation. J. Vasc. Surg., 12: 291, 1990.

26- HERTZER N.R., BENA J.F. and KARAFA M.T.: A personal experience with direct reconstruction and extraanatomic bypass for aortoiliofemoral occlusive disease. J. Vasc. Surg., 45 (3): 527-35, 2007.

27- SALVATORE T.S., BRADLEY M.S., ROBERT J.F., ADAM W.B., CATHERINE K.C., ALYSON L.W., SCOTT A.B. and THOMAS S.H.: Outcomes after redo aortobifemoral bypass for aortoiliac occlusive disease. J. Vasc. Surg., 60 (2): 346-55, 2014. 
28- MALONE J., GOLDSTONE J. and MOORE W.: Autogenous profundaplasty: The key to long-term patency in secondary repair of aortofemoral graft occlusion. Ann. Surg., 188 (6): 817-23, 1987.

29- BERNHARD W.M., RAY L.I. and MILITELLO J.P.: The role of angioplasty in the profunda femoris artery in revascularization of the ischemic limb. Surg. Gynecol. Obstet., 142: 840, 1986.

30- BERGUER R., HIGGINS R. and COTTON L.: Geometry, blood flow, and reconstruction of the deep femoral artery. Am. J. Surg., 130: 68, 1985.
31- PATEL A.P., LANGAN E.M., TAYLOR S.M., SNYDER B.A., CULL D.L. and CARSTEN C.G.: Has the emergence of endovascular treatment for aneurysmal and occlusive aortic disease increased the complexity and difficulty of open aortic operations? Ann. Vasc. Surg., 18: 212-7, 2004.

32- WRESSNEGGER A., KINSTNER C. and FUNOVICS M.: Treatment of the aorto-iliac segment in complex lower extremity arterial occlusive disease. J. Cardiovasc. Surg. (Torino), 56 (1): 73-9, 2015.

\section{Tتائج تجاوز الآبهر الفخذى بالشرين الصناعى لمعيار

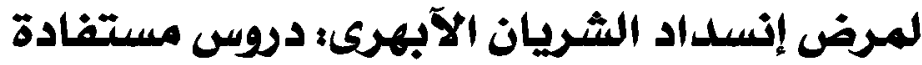

$$
\text { الهدف: تقييم نتائج تقنية تجاوز الآبهر الفخذى بالشرين الصناعى لمعيار TASC II C, D لمرض إنسداد الشريان الآبهرى. }
$$

المرضى وطرق العلاج: آجريت هذه الدراسة المستقبلية على 19 مريضاً يعانون من أعراض آفات تصلب الثرايين الآبهرى لمعيار

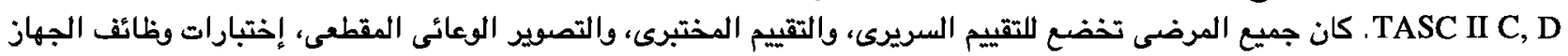

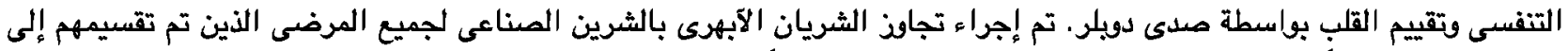

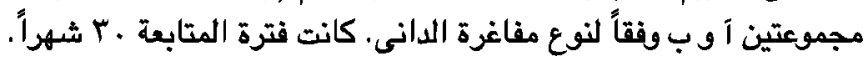

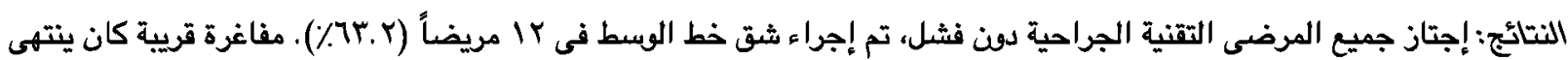

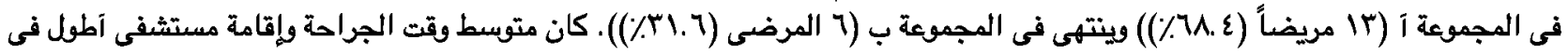

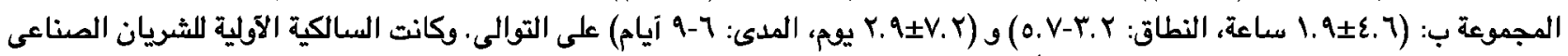
.

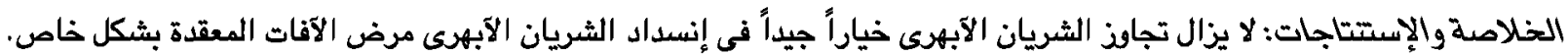

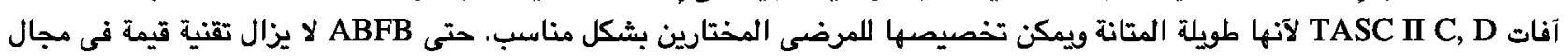

